\title{
INFLUENCE OF DAMAGE ON THE TENSILE BEHAVIOUR OF PURE ALUMINIUM REINFORCED WITH $\geq 40$ VOL. PCT ALUMINA PARTICLES
}

\author{
M. KOUZELI, L. WEBER, C. SAN MARCHI and A. MORTENSEN $\dagger$ \\ Laboratory for Mechanical Metallurgy, École Polytechnique Fédérale de Lausanne, 1015 Lausanne, \\ Switzerland
}

( Received 23 May 2001; accepted 12 July 2001)

\begin{abstract}
Particle reinforced composites are produced by infiltrating $\mathrm{Al}_{2} \mathrm{O}_{3}$ particle beds with high purity Al (99.99\%). These materials feature 40-60 vol. pct reinforcement homogeneously distributed in a pore-free matrix. Their tensile behaviour is studied as a function of reinforcement size and shape. Internal damage, in the form of particle fracture and matrix voiding, occurs from the onset of plastic straining. Its evolution with strain is monitored through changes in (i) stiffness and (ii) peak stress after incremental plastic straining and annealing. The influence of damage on the flow curves of the composites can be accounted for using basic postulates of continuum damage mechanics. Failure strains vary between 2 and $4 \%$, and are a function of the rate of damage accumulation. An expression is derived to predict elongation to failure of damaging materials that fail by tensile instability, which gives good agreement with the experimental observations. (C) 2001 Published by Elsevier Science Ltd on behalf of Acta Materialia Inc.
\end{abstract}

Keywords: Composites; Dislocations; Aluminium; Stress-strain relationship measurements; Damage

\section{INTRODUCTION}

The tensile elongation of materials which combine a ductile matrix with a stiff and brittle second phase, such as near-eutectic Al-Si alloys or ceramic particle reinforced metal matrix composites (PRMMCs), is significantly lower than that of the matrix alone. It is generally believed that this is due to the accumulation of microstructural damage with strain. A concise correlation, however, between damage and overall ductility levels has not yet been elucidated [1].

Damage accumulation in this class of materials is a complex physical phenomenon which depends strongly on microstructural characteristics. For PRMMCs two main damage mechanisms have been reported: reinforcement fracture, and matrix voiding at or near the matrix-reinforcement interface [2-18]. Various studies have also shown that microstructural damage increases gradually with tensile deformation and is directly linked to tensile strain and/or tensile stress (e.g. [12, 18-28]). Reinforcement characteristics have proven to be influential in determining the predominant damage micromechanisms and their rate of accumulation. In particular, particle fracture is

$\dagger$ To whom all correspondence should be addressed. E-mail address: mortensen@dmx.epfl.ch (A. dominant for large reinforcement sizes and the fraction of particles that break increases as the volume fraction or average size of the reinforcement increases; this has been documented both by direct measurements on polished samples $[2,3,8,10,12-$ $14,18,21,29-31]$ and indirect measurements with a sensitivity to brittle fracture (e.g. elastic modulus monitoring and acoustic emission measurements) [18, 20-22, 25, 26, 32-35]. The effect of reinforcement shape on its propensity to fracture has also been investigated but findings reported in the literature are not consistent. Li et al. [8] and Vedani et al. [32] report small differences in the rate of damage accumulation depending on particle shape, while other studies point to a distinct link between the fracture of a reinforcement and its shape and/or aspect ratio: the higher the angularity and/or the aspect ratio of the reinforcement the more prone it is to cracking [2, 3, 36-39]. Conversely, there is evidence that microstructural damage changes from reinforcement fracture to matrix voiding at or near the matrixreinforcement interface as the reinforcement size, volume fraction, angularity or aspect ratio decrease [10, 19, 34, 36, 40, 41].

Several analyses have been developed to explain the experimentally observed trends in damage of particle reinforced composites, with the goal of understanding and predicting composite tensile behaviour. 
Essentially, modelling can be split into two principal tasks: determining the partition and distribution of stress in each of the constituents and deriving laws for the nucleation and accumulation of damage. Determination of the stress/strain partitioning has been attempted by a variety of methods, including the modified shear-lag model [39, 42], the mean field approach [43-45], and finite element methods (FEM) $[27,28,46-50,27,28,46-50]$. Only FEM can provide information on the evolution of local stress/strain distributions at (or near) the reinforcements, which are critical to the nucleation of damage. As such, these methods have proven to be an indispensable tool in understanding damage evolution and its dependence on reinforcement characteristics in particle reinforced composites. The understanding provided by these FEM models, however, is generally not accompanied by predictive powers since most of these models are based on axisymmetric unit cells containing one particle; these cells, therefore, cannot describe the accumulation of damage during tensile straining and the collective effect it has on the macroscopic composite properties, including the link that exists between damage accumulation and strain to failure.

An alternative method to couple damage accumulation with a material's constitutive behaviour is based on Continuum Damage Mechanics (CDM). In $\mathrm{CDM}$, damage is considered to be an internal (scalar or tensorial) state variable, $D$, which describes the effects of microscopic events phenomenologically and macroscopically. In the simplest case of uniaxial deformation [51], $D$ is a scalar which links the truemacroscopic-stress, $\sigma$, to the effective stress, $\tilde{\sigma}$, as

$$
\tilde{\sigma}=\frac{\sigma}{1-D}
$$

The postulate of strain equivalence in CDM considers the strain constitutive equation of a damaging material to be the same as that of (the equivalent) non-damaging material except that the usual stress is replaced by the effective stress [52]. Applied to uniaxial elastic deformation, this leads to the definition of $D$ on the basis of a change in the elastic modulus,

$$
D=D_{E}=1-\frac{E}{E_{0}}
$$

where $E$ is the elastic modulus of the damaged material and $E_{0}$ that of the undamaged material (other postulates exist which relate damage to the constitutive equations of a material, such as the equivalent stress and equivalent energy postulates [53]). It would be of interest to test the viability of such CDM approaches to modelling composite damage and its link to composite ductility.
In a previous publication [18] we studied the accumulation of internal damage in infiltrated particle reinforced composites $\left(\mathrm{Al}_{2} \mathrm{O}_{3}-\mathrm{Al}\right.$ and $\left.\mathrm{B}_{4} \mathrm{C}-\mathrm{Al}\right)$, using two damage parameters, namely $D_{E}$ [equation (2)] and $D_{\rho}$ (the relative decrease in density, equal to the volume fraction porosity). We showed that both damage parameters change as a function of microstructural characteristics and tensile strain, and we provided a link between their respective magnitudes and the micromechanisms of damage accumulation. In what follows we present new experiments on pure aluminium reinforced with $\geq 40$ vol. pct alumina particles, in which we compare two different types of particulate alumina (angular and polygonal). We show that significant differences exist between the two reinforcements with regard to damage accumulation, and that the strain equivalence postulate of CDM adequately describes the influence of damage on the composite tensile behaviour. We then draw from this conclusion to link the strain to failure of these materials to the rate at which they accumulate damage.

\section{EXPERIMENTAL PROCEDURES}

\subsection{Materials}

Packed-beds of alumina powder were infiltrated with high-purity aluminium $(99.99 \%)$ to produce composites reinforced with 40-60 vol. pct ceramic $\left(1199 / \mathrm{Al}_{2} \mathrm{O}_{3} / \sim 50 \mathrm{p}\right)$. Two types and several average particle sizes of $\alpha-\mathrm{Al}_{2} \mathrm{O}_{3}$ particles were used to vary the composite microstructures. Fused $\alpha-\mathrm{Al}_{2} \mathrm{O}_{3}$ powders that are manufactured for the abrasive industry were purchased from Treibacher Schleifmittel (Laufenburg, Germany). These angular particulates are $99.5 \%$ pure and were received in several FEPAspecified grit designations: F220, F320, F600, F1000, which correspond to average nominal particle sizes of 58, 29, 9.3, and $4.5 \mu \mathrm{m}$ respectively. High-purity $(>99.9 \%) \alpha-\mathrm{Al}_{2} \mathrm{O}_{3}$ particles with a polygonal morphology were purchased from Sumitomo Chemical (Osaka, Japan). These powders are produced by hydrolysis and supplied in grades that correspond to average particle sizes. Composites have been prepared with AA-10 and AA-18 grades; nominal particles sizes are 10 , and $18 \mu \mathrm{m}$ respectively. All asreceived powders were examined with a Scanning Electron Microscope (SEM) to determine their quality. In the interest of brevity, a short-hand designation is used hereafter to distinguish the various composites: a number, which denotes the nominal particle size, followed by the letter A for composites reinforced with abrasive grade powder, or $\mathrm{P}$ for composites reinforced with the polygonal powder.

The concentration of the ceramic in the composites was determined by high-precision density measurements based on an immersion technique. Quasistatic tensile tests were conducted on a screw-driven universal-testing machine using sub-sized dogbone samples 
[18]. Longitudinal displacements were measured with a clip-on extensometer over a $10 \mathrm{~mm}$ gauge length. True stress-true strain curves were calculated from the load-extension data assuming volume constancy [54]; this is a valid assumption since relative volume changes in the present materials during tensile straining (due to damage accumulation) are small and on the order of $10^{-3}$ [18]. As-cast materials and tensile samples that were loaded to failure were sectioned, polished (according to procedures outlined in [18]), and examined under an optical microscope and a scanning electron microscope (SEM).

\subsection{Damage monitoring}

2.2.1. Young's modulus evolution. The initial Young's modulus of the composites, $E_{0}$, was measured upon repeated unload-reload segments after a small increment of plastic strain, less than $0.2 \%$ [55]. These stress-strain cycles are experimentally tailored so as to minimise microplasticity effects in the soft pure aluminium matrix (c.f. [18] for details). To monitor the Young's modulus of the composite as a function of strain, intermittent unload-reload cycles were repeated at strain increments of $0.2 \%$, the implemented cycles being identical to the ones performed at strains $<0.2 \%$ for the determination of $E_{0}$. From these measurements the damage parameter $D_{E}$ is calculated [equation (2)].

2.2.2. Stress evolution. In a separate series of experiments, matrix annealing after incremental plastic straining was carried out in order to measure the effect of irreversible microstructural damage on the flow stress and stiffness of the composites, free of the intrinsic (and reversible) evolution of matrix strain hardening. Tensile strain increments of either $0.5 \%$ or $1 \%$ were, thus, imposed on selected composite samples; in-between each cycle an annealing heattreatment was conducted. The annealing treatment consists of placing the strained sample in a preheated furnace at $340^{\circ} \mathrm{C}$ for $2 \mathrm{~h}$, and then letting it cool slowly in the furnace over a period of $20 \mathrm{~h}$ (as is suggested in [56] for stress relief in pure aluminium). This same heat-treatment is conducted on these tensile samples before straining to achieve a clearly defined reference state. The peak stress for each strain increment was then used to compute a stress-based damage parameter $D_{\sigma}$ :

$$
D_{\sigma}=1-\frac{\sigma}{\sigma_{0}}
$$

where $\sigma$ is the peak stress for a given strain increment and $\sigma_{0}$ is the peak stress for the first increment. The stiffness of the samples was also measured at each strain increment following the procedures outlined in [18]. A schematic description of these experiments is given in Fig. 1.

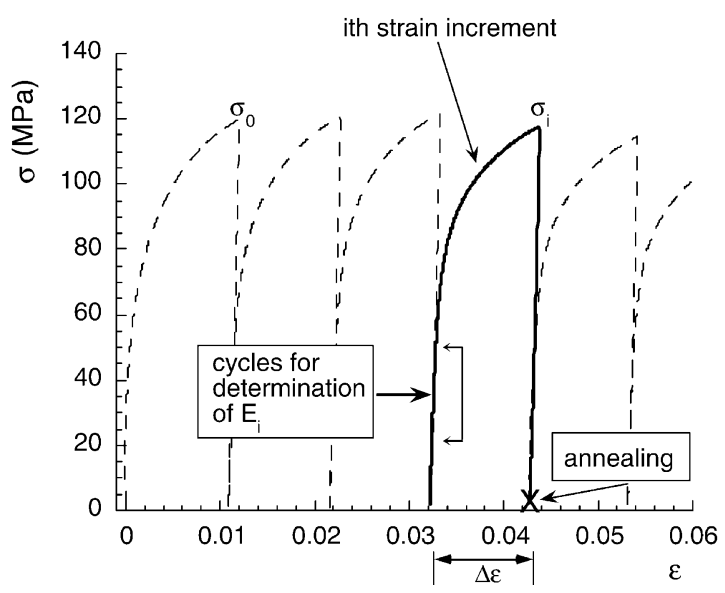

Fig. 1. Schematic depiction of the experiments combining incremental plastic straining and annealing.

\section{RESULTS}

\subsection{Microstructural characterisation and tensile properties}

Figure 2 compares the morphology and surface quality of the two types of particles used in this study.

(a)

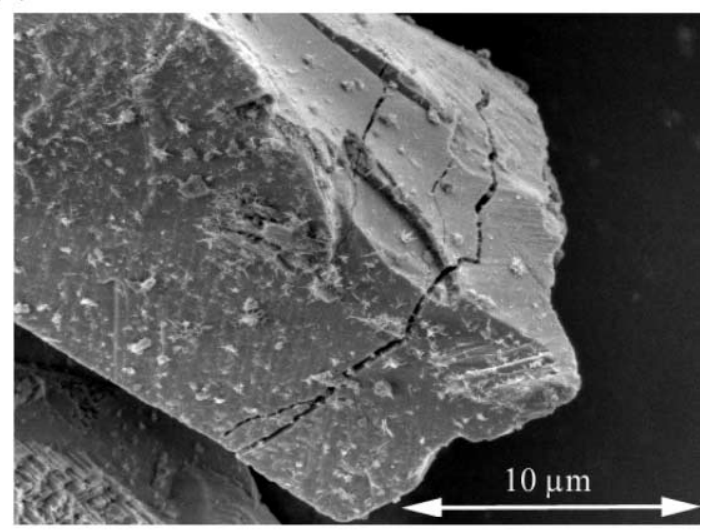

(b)

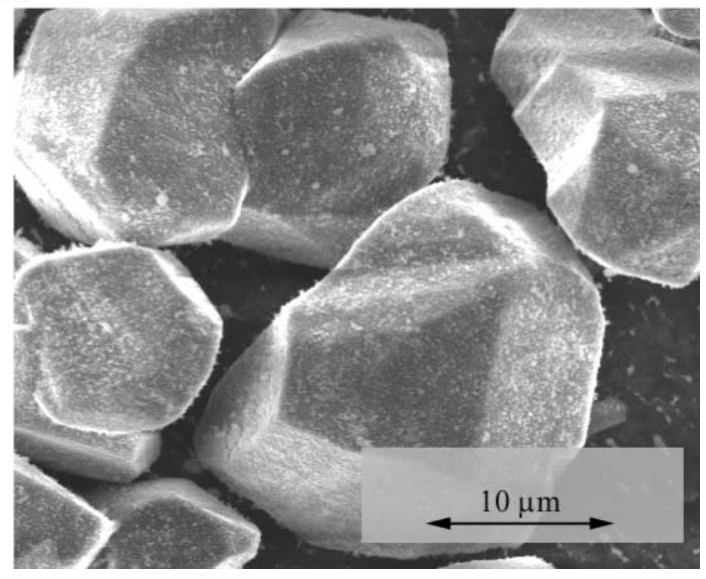

Fig. 2. High magnification SEM micrographs of powders (a) F320 and (b) AA-10. 


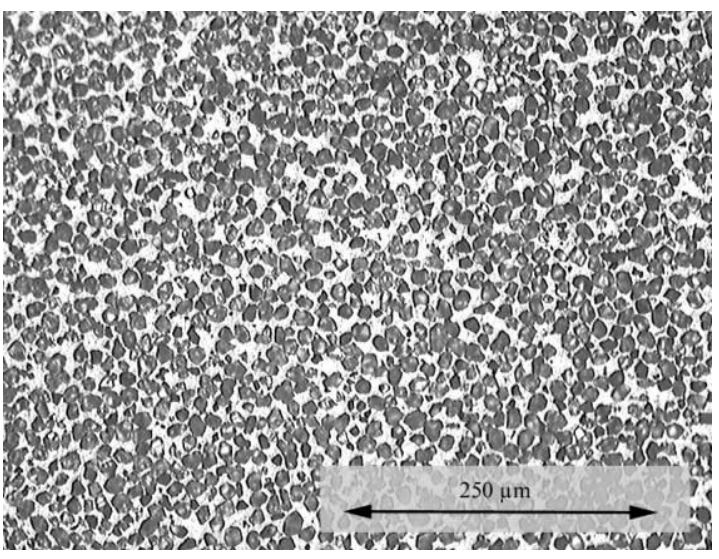

Fig. 3. Optical micrograph of as-cast composite 10P.

The particles in both powders are near-equiaxed. Angular $\mathrm{Al}_{2} \mathrm{O}_{3}$ particles are characterised by sharp corners and contain a certain number of visible surface cracks [Fig. 2(a)]. The surface crack density was observed to increase with increasing average size of reinforcement, and even in the powders with an average particle size of $4.5 \mu \mathrm{m}$ such cracks were readily visible. A smooth surface and no defects summarise the appearance of the polygonal $\mathrm{Al}_{2} \mathrm{O}_{3}$ particles [Fig. 2(b)].

As-cast composite microstructures feature a homogeneous distribution of $\mathrm{Al}_{2} \mathrm{O}_{3}$ particles in a pore-free aluminium matrix (Fig. 3) (and figure 1 of Ref. [18]). In all composites the reinforcing particles have a number of contact points with their neighbours; this is a direct consequence of the high volume fractions characteristic of these composites. Basic physical and tensile properties of the composites are summarised in Table 1; typical flow curves are depicted in Fig. 4. The yield stress of the composites, $\sigma_{y}$, was determined at $0.02 \%$ offset strain (the traditionally used $0.2 \%$ offset stress was deemed to be unrepresentative of yielding, due to significant microplasticity from the onset of loading). For composites which fail due to tensile instability, i.e. 58A, 29A, $18 \mathrm{P}$ and $10 \mathrm{P}$, the failure strain is considered to be the necking strain as determined by Considere's criterion. For composites $10 \mathrm{~A}$ and $5 \mathrm{~A}$ that fail before Considere's criterion is met, the maximum strain at failure is reported.

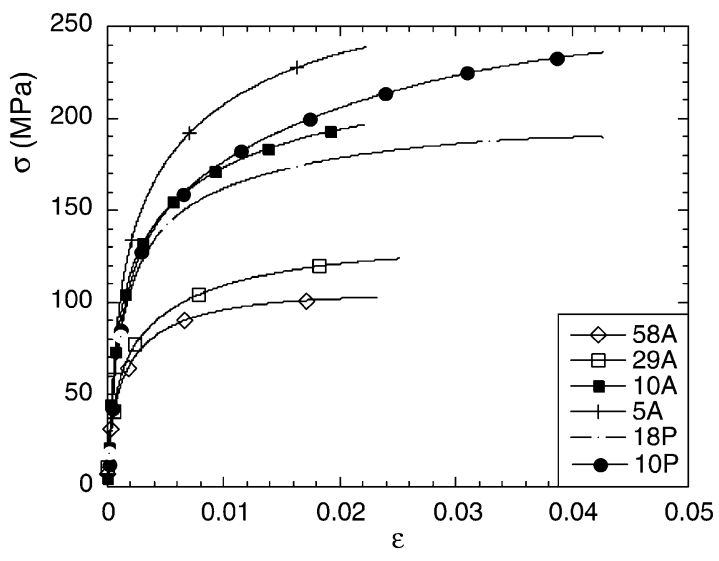

Fig. 4. Typical composite flow curves.

The Young's modulus of the composites varies solely as a function of the volume fraction reinforcement; all experimental data points fall on a single trend line (Fig. 5). The composite yield stress, on the other hand, is primarily a function of reinforcement size, increasing with decreasing reinforcement size. In general, the flow stress of the composite follows

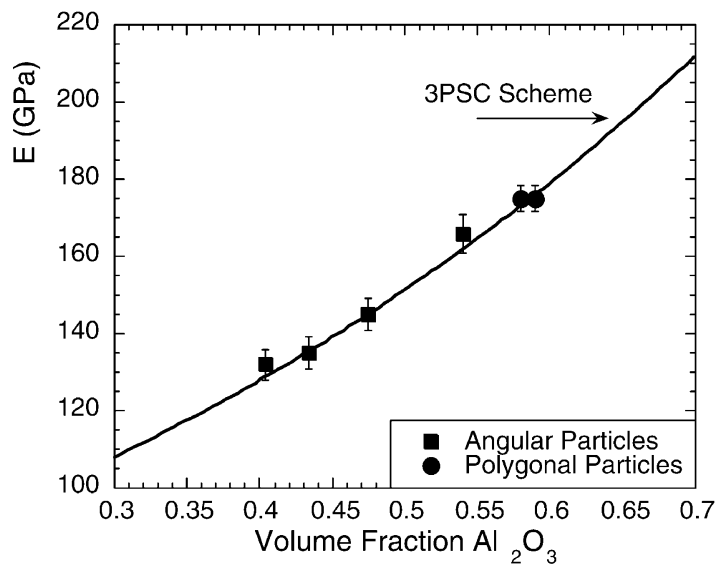

Fig. 5. Young's modulus evolution as a function of volume fraction $\mathrm{Al}_{2} \mathrm{O}_{3}$; the symbols correspond to experimental data points and the solid line to predictions of a three-phase selfconsistent scheme. The elastic properties used in the calculations are: $E_{\mathrm{Al}}=69 \mathrm{GPa}, E_{\mathrm{Al}_{2} \mathrm{O}_{3}}=400 \mathrm{GPa}, v_{\mathrm{Al}}=0.345$, $v_{\mathrm{Al}_{2} \mathrm{O}_{3}}=0.22[87,88]$.

Table 1. Basic properties of $\mathrm{Al}_{2} \mathrm{O}_{3}-\mathrm{Al}$ composites produced for this study

\begin{tabular}{|c|c|c|c|c|c|c|c|}
\hline $\begin{array}{l}\text { Composite } \\
\text { designation }\end{array}$ & Particle specification & $\begin{array}{c}\text { Average } \\
\text { particle size } \\
(\mu \mathrm{m})\end{array}$ & $\begin{array}{c}\text { Volume } \\
\text { fraction } \mathrm{Al}_{2} \mathrm{O}_{3}\end{array}$ & $E_{0}(\mathrm{GPa})$ & $\sigma_{0.02 \%}(\mathrm{MPa})$ & UTS (MPa) & $\varepsilon_{\mathrm{f}} \%$ \\
\hline $58 \mathrm{~A}$ & F220 & $58^{\mathrm{a}}$ & 0.475 & 145 & 42 & 101 & $1.9^{\mathrm{c}}$ \\
\hline $29 \mathrm{~A}$ & F320 & $29^{\mathrm{a}}$ & 0.446 & 140 & 43 & 127 & $3.2^{\mathrm{c}}$ \\
\hline $10 \mathrm{~A}$ & F600 & $9.3^{\mathrm{a}}$ & 0.54 & 166 & 68 & 189 & 1.8 \\
\hline $5 \mathrm{~A}$ & F1000 & $4.5^{\mathrm{a}}$ & 0.404 & 132 & 89 & 249 & 2.7 \\
\hline $18 \mathrm{P}$ & AA-18 & $18^{\mathrm{b}}$ & 0.59 & 175 & 62 & 189 & $4.1^{c}$ \\
\hline $10 \mathrm{P}$ & AA-10 & $10^{\mathrm{b}}$ & 0.58 & 175 & 65 & 229 & $4.5^{\mathrm{c}}$ \\
\hline
\end{tabular}

\footnotetext{
a FEPA (Federation of European Producers of Abrasives) standard 42-1984 R 1993

b Manufacturer classifications.

Tensile instability strain.
} 
this same trend. Particle shape does not seem to strongly influence the composite yield stress; however, at higher strains, there is evidence of a divergence in the stress-strain curves of composites 10A and 10P (Fig. 4), which are equivalent in all their microstructural characteristics (volume fraction and size of reinforcements) save particle type. In specific, the polygonal reinforcements yield composites with a higher ultimate tensile strength than the angular ones. Failure strains are also higher in composites containing polygonal $\mathrm{Al}_{2} \mathrm{O}_{3}$ particles and are on the order of $4 \%$. For composites reinforced with angular particles failure strains are $2.5 \%$ on average. For both type A and type $\mathrm{P}$ composites that fail due to necking, the failure strain increases with decreasing particle size, Table 1. This trend is not conserved, however, when the composites that fail before necking are included in the comparison.

\subsection{Micromechanisms and accumulation of damage}

Tensile straining of the composites results in the accumulation of irreversible microstructural damage in the form of particle fracture and matrix voiding (Fig. 6). Particle fracture was observed in all composite systems and seems to be activated by particleparticle interactions. Indeed cracks in particles often nucleate at (or near) particle-particle contact points [Fig. 6(a) and (b)] (see also figure 2 of [18]). The propensity for particle fracture increases as the reinforcement size increases, while the occurrenceor not-of matrix voiding depends on the specifics of the microstructure: composites reinforced with angular $\mathrm{Al}_{2} \mathrm{O}_{3}$ particles rarely damage by the nucleation and growth of matrix voids, whereas with polygonal $\mathrm{Al}_{2} \mathrm{O}_{3}$ matrix voiding occurs about as frequently as particle fracture. These voids nucleate in areas of the matrix which are highly constrained, i.e. in areas where the interparticle spacing is smaller than average [Fig. 6(c)].

Indirect measurements of damage, $D_{E}$ and $D_{\sigma}$, support the above observations: (i) composites that contain larger reinforcements accumulate damage at a higher rate, evident by the evolution of both damage parameters [Figs 7(a) and 8]; and (ii) for equivalent particle sizes, composites reinforced with angular $\mathrm{Al}_{2} \mathrm{O}_{3}$ particles suffer a greater loss in stiffness in comparison to those reinforced with polygonal $\mathrm{Al}_{2} \mathrm{O}_{3}$ particles [Fig. 7(b)]. The experimental scatter of the data collected during a "stress-annealing" experiment (Fig. 9) is notably larger than the data from experiments where no annealing intervenes (Fig. 7). This is because the sample was removed from the tensile testing apparatus after each loading cycle and then repositioned in the grips after annealing, leading to an increase in errors related to specimen alignment. A comparison of damage parameters $D_{\sigma}$ and $D_{E}$ as determined during a "stress-annealing" experiment on composite A58 is represented in Fig. 9; it is clear that the evolution of $D_{\sigma}$ as a function of cumulative plastic strain follows closely that of $D_{E}$ for the imposed (a)

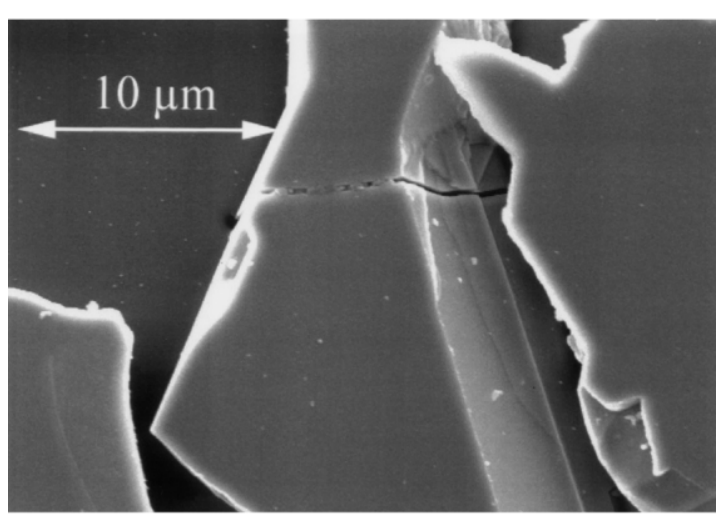

(b)

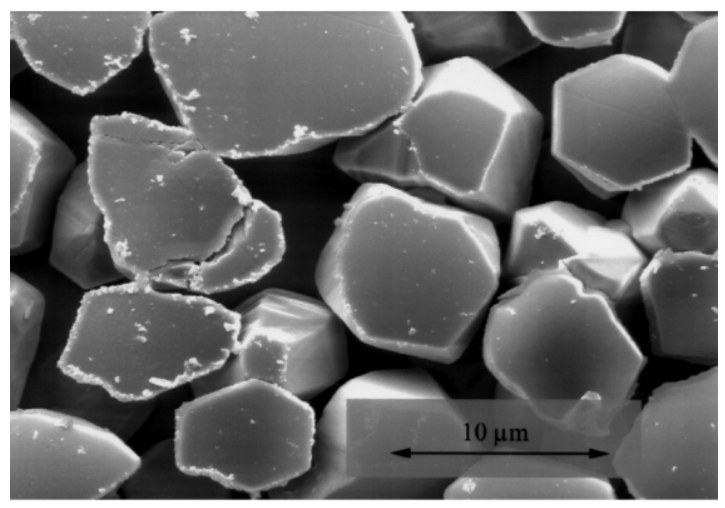

(c)

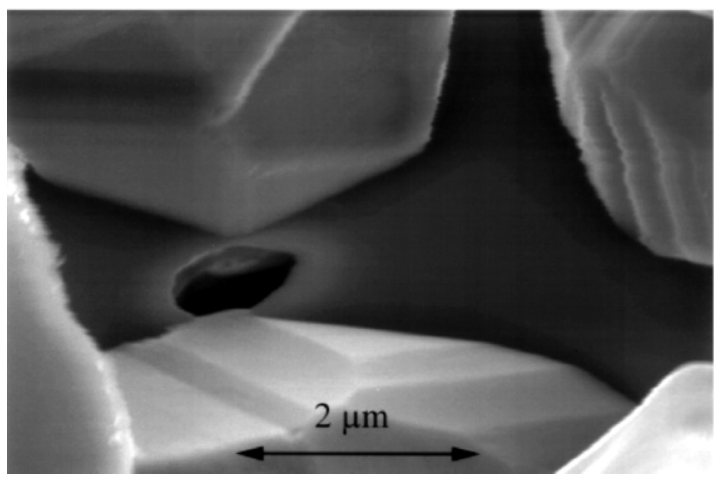

Fig. 6. SEM images depicting various micromechanisms of damage: (a) particle fracture in composite $29 \mathrm{~A}$, (b) idem in composite 10P, and (c) matrix voiding in composite $10 \mathrm{P}$.

stress-strain cycles. Note, also, how the annealing heat treatments in-between strain increments serve to significantly increase the amount of cumulative plastic strain that the composites can sustain.

\section{DISCUSSION}

\subsection{Young's modulus and yield stress}

A three-phase self-consistent continuum model [57] (Fig. 5), clearly captures the elastic response of the present composites and its dependence on 
(a)

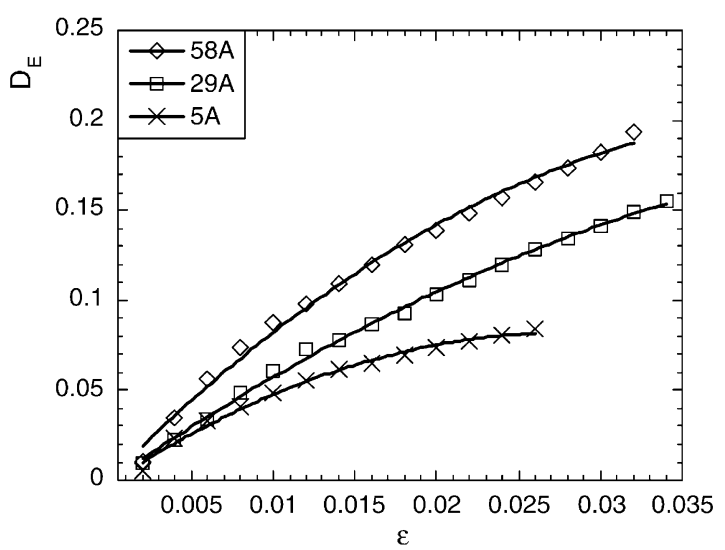

(b)

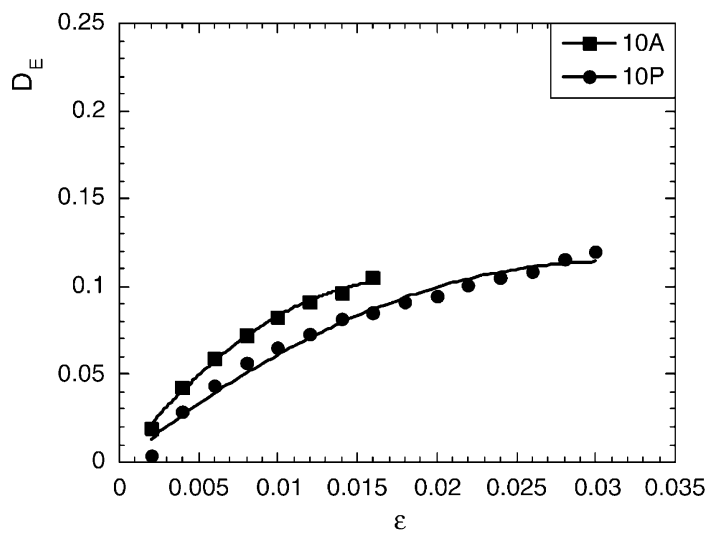

Fig. 7. Evolution with strain of stiffness-derived damage parameter $D_{E}$ : (a) effect of particle size, and (b) effect of particle shape.

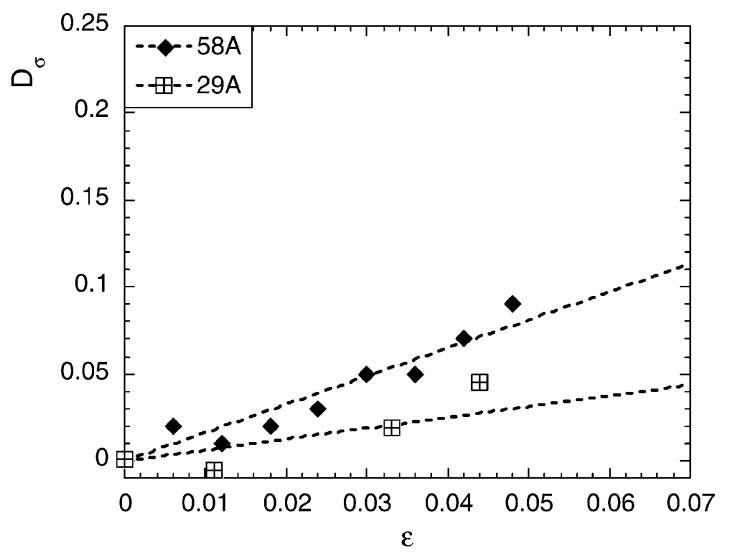

Fig. 8. Evolution with strain of stress-derived damage parameter $D_{\sigma}$ : effect of particle size.

reinforcement volume fraction. The shape of the particles does not exert a strong influence on the elastic modulus of these materials, in accordance to several other studies [58-60]. This is to be expected, since both types of reinforcement (angular and polygonal

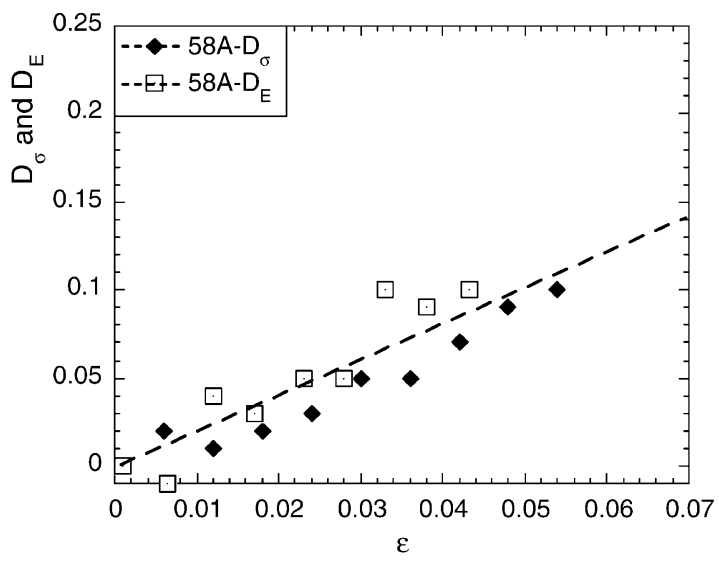

Fig. 9. Evolution with strain of stress-derived damage parameter $D_{\sigma}$ and stiffness-derived damage parameter $D_{E}$ in composite $58 \mathrm{~A}$ for a "stress-annealing" experiment.

particles) yield composite microstructures which can be modelled as stiff equiaxed polyhedra surrounded by a soft metal shell (Fig. 3). That the specific shape of low aspect ratio reinforcements does not significantly influence the elastic properties of composite materials has been shown explicitly in the literature both by analytical [61] and numerical models [6264].

The yield stress of the present composites exhibits a strong dependence on reinforcement size, Fig. 4 and Table 1. The particular interdependence has been noted in several other studies of particle reinforced metals [13, 29, 65-69], and has been attributed primarily to the size dependent generation of geometrically necessary dislocations upon cooldown from the processing temperature $[70,71]$. The size dependence of the yield stress in the present composites is analysed in detail elsewhere [72].

\subsection{Tensile flow curves}

4.2.1. True vs effective stress. "Stress annealing" experiments have the advantage of providing the synchronous evolution of two different damage parameters: the stress-based damage parameter $D_{\sigma}$ and the modulus-based damage parameter $D_{E}$ (Fig. 9). Comparison of these two parameters for material 58A shows that, although $D_{\sigma}$ is slightly lower than $D_{E}$ (approximately $10 \%$ lower, in contrast to the density based damage parameter $D_{\rho}$, which is 10 to 100 times lower [18]), within experimental scatter a common line can be drawn through both sets of data points (Fig. 9). One can thus consider $D_{E}$ and $D_{\sigma}$ to be equivalent at all strains, in accordance with the strain equivalence postulate of CDM, which assumes that damage accumulation affects the elastoplastic flow stress and the stiffness evolution of the composite similarly [52]. The applicability of this postulate, however, cannot be expected a priori given the different laws governing elastic and plastic deformation. 
To further test the strain equivalence postulate, i.e. equations (1) and (2) expressed as

$$
\tilde{\sigma}=\sigma /\left(1-D_{E}\right)
$$

we compare the effective stress-strain curves for similar composites that damage at different rates. Consider composites 10A and 10P: they have equivalent microstructures (size and volume fraction of particles) and yield stresses; however, they accumulate damage $d \mathrm{D}_{\mathrm{E}} / \mathrm{d} \varepsilon$ at a different rate as a consequence of the varying quality of the respective reinforcing particles. This is manifest in the tensile curves of the composites, which are almost identical at low strains but start diverging after about $1 \%$ strain. If the strain equivalence postulate is valid, then the curves correlating the effective stress $\tilde{\sigma}$ to the strain $\varepsilon$ determined from equation (4) should be identical for these two composites. It is evident from Fig. 10 that this is indeed the case. Even in the presence of extensive plastic deformation, equation (4) can, thus, properly describe the effective tensile behaviour of the present materials.

4.2.2. Constitutive behaviour. Plots of $\ln (\tilde{\sigma})=f(\ln \varepsilon)$ reveal a straight-line correlation for all composites at strains higher than $1 \%$ (Fig. 11). Furthermore, these straight lines are all essentially parallel. The "undamaged" effective composite flow curves can, thus, be written as $\tilde{\sigma}=g\left(V_{\mathrm{p}}, D\right) \bullet f(\varepsilon)$, where $f(\varepsilon) \sim \mathcal{E}^{n}$, and $n=0.2( \pm 0.01)$. Including the lowstrain regime, the Ramberg-Osgood equation fits well these effective tensile curves (Fig. 12). The only parameters needed to be varied in order to fit the specific law to each of the effective curves are (i) $\sigma_{\mathrm{y}}$, which is a function of the volume fraction and average size of the reinforcements [70], and (ii) $E_{0}$, which is a known function of the volume fraction ceramic particles [57]. That the strain hardening exponent $n$ is identical for all composites indicates that the overall strain hardening behaviour of these materials does not

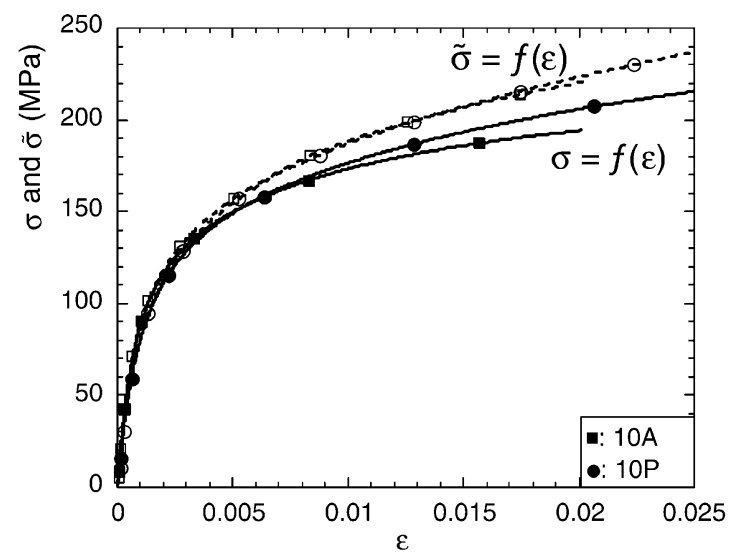

Fig. 10. True and effective stress vs strain for composites 10A and $10 \mathrm{P}$.

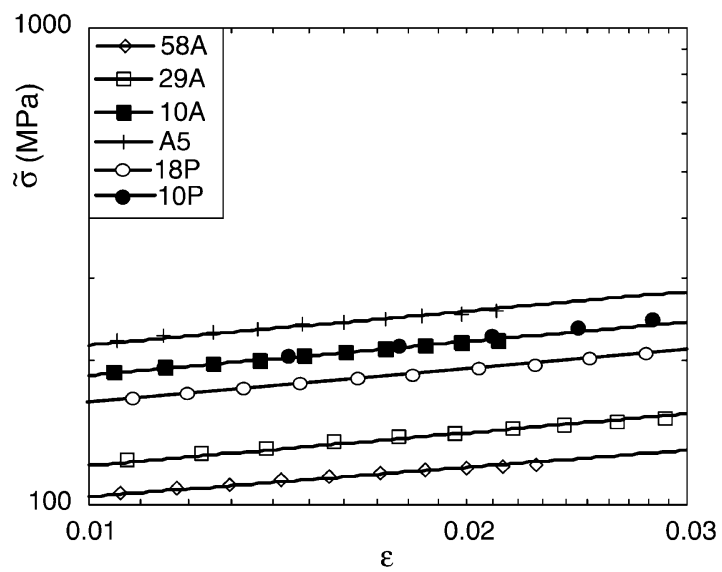

Fig. 11. $\mathrm{Ln}$-ln plots of effective stress vs strain for the various $\mathrm{Al}_{2} \mathrm{O}_{3}-\mathrm{Al}$ composites.

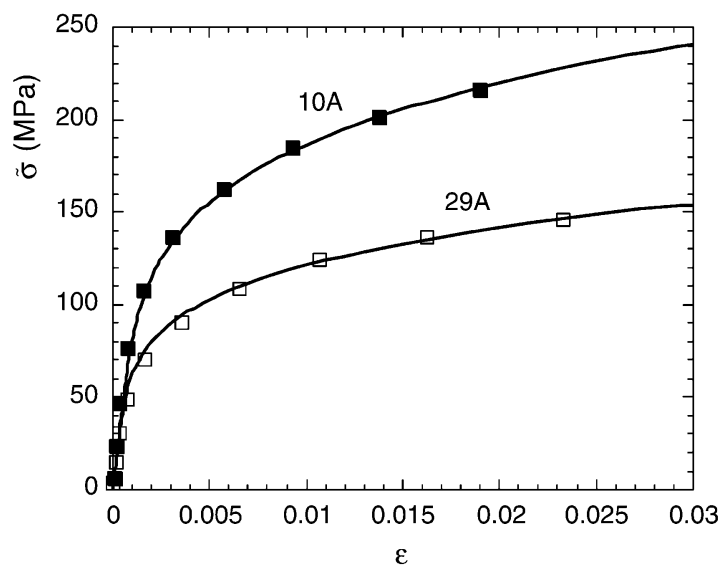

Fig. 12. Effective tensile curves for selected composites. Symbols denote the experimentally determined curves and full lines are curve fits of the expression: $\varepsilon=\tilde{\sigma} / E_{0}+\alpha\left(\sigma_{\mathrm{y}} / E_{0}\right)\left(\tilde{\sigma} / \sigma_{\mathrm{y}}\right)^{1 / n}$, where $\alpha$ is a dimensionless constant equal to $3 / 7$.

depend on microstructural length scales - unlike their yield strength $\sigma_{\mathrm{y}}$. The value for the strain hardening exponent of 0.2 correlates well to the respective exponent in bulk cold-worked Al 99.99\% (between 10 and $20 \%$ reduction) containing a high initial dislocation density [73].

\subsection{Damage accumulation}

4.3.1. Matrix voiding. Two damage mechanisms have been observed in the present composites: particle fracture and matrix voiding. The latter mechanism is important in the polygonal alumina reinforced composites and occurs in areas of the matrix between particles, which are closely spaced in the tensile direction [Fig. 6(c)]. These regions are expected to experience large triaxial stresses [50,74], and thus are the most likely sites for the nucleation of voids related to ductile failure [75]. Furthermore, the size of the ductile voids in any given composite is relatively uniform (Figure 3(b) of Ref. [18]). This seems to indicate that void nucleation, rather than 
void growth, is the dominant component in the evolution of matrix-void volume fraction of the present composites. While closely spaced particles are responsible for the high triaxial stresses which lead to matrix voiding, these same particles act as barriers to void growth. A similar conclusion was drawn by Huang et al. [76] for composites containing large clusters of particles, albeit in lower concentrations. Such clusters have a local microstructure similar to the overall-homogeneous-microstructure of the composites produced in this study, which may explain the similarity.

\subsubsection{Particle fracture-influence of particle size.}

In [18] it was shown that even in the presence of matrix voiding the accumulation of damage as measured through $D_{E}$ is dominated by particle fracture when both mechanisms are active (within the limits, of course, of reinforcement sizes and volume fractions studied here and in [18]), and that the rate of damage accumulation is lower for smaller reinforcements. The latter point is further demonstrated in Figs 7(a) and 8. This size-dependence of particle fracture can be rationalised in light of the SEM images of the starting powders (Fig. 2): powders containing large particles are characterised by a greater surface-defect population than powders containing small particles. As such, large particles fracture at a higher rate than small particles. Other studies have also shown this size-dependence of the rate of damage accumulation (e.g. $[2,12,25,26,31,38])$, which is consistent with a statistic failure criterion commonly applied to ceramic materials [42].

4.3.3. Particle fracture-influence of particle type.

For roughly equal volume fractions and reinforcement size, composites reinforced with angular $\mathrm{Al}_{2} \mathrm{O}_{3}$ particles accumulate damage at a higher rate than composites with polygonal $\mathrm{Al}_{2} \mathrm{O}_{3}$ particles [Fig. 7(b)]. SEM images of the angular $\mathrm{Al}_{2} \mathrm{O}_{3}$ powders reveal sharp cracks on the surface of the particles [Fig. 2(a)]. In the polygonal $\mathrm{Al}_{2} \mathrm{O}_{3}$ powders, on the other hand, no surface defects were evident; this is probably due to the fact that no size reduction processes are involved in their production [77]. These differences in initial flaw population can explain why the polygonal $\mathrm{Al}_{2} \mathrm{O}_{3}$ particles are intrinsically stronger than their angular counterparts, explaining in turn the lower rate of damage accumulation in composites reinforced with polygonal particles.

Particle shape can also influence the rate of damage accumulation in particle reinforced metals. Qin et al. [59] and Chen et al. [78] have shown via FEM analysis that sharp angles in particles, which are completely surrounded by the metal matrix, act as stress concentrators, effectively increasing their probability of failure. In the present high volume fraction composites each reinforcement has several close neighbours with which it is in direct contact. The application of tensile stresses and the subsequent plastic deformation of the composites necessitate the move- ment of reinforcements to accommodate for flow of the matrix around them. These slight rearrangements of the reinforcement relative to the metal matrix and to one another induce load transfer at the contact points between neighbouring particles, leading to high stress concentrations at (or near) these points. The resulting (compressive) contact stress $q$ is an inverse function of the contact area, and thus related to the contact tip radius $R$ as $q=f\left(R^{-2 / 3}\right)$, c.f. Ref. [79]. The maximum tensile stress resulting from these contact stresses acts radially to the contact area and is linearly dependent on $q$, and can induce particle fracture at the contacts or, in the case of the angular particles, activate existing cracks near the contacts. Figures 6(a) and (b), and figure 2 of Ref. [18] clearly show that particle fracture can be attributed to such particle-particle interactions. Since the angular particles are characterised by sharp corners, they will on average have a smaller contact radius as compared to the blunt polygonal particles, thus higher stresses will be induced in the particles as they impinge on one another. In summary, composites reinforced with angular particles tend to accumulate damage at a higher rate than composites reinforced with polygonal particles as a consequence of (i) a higher concentration of defects in the starting powder, and (ii) higher contact stresses between particles as a result of the angular nature of the particle.

4.3.4. Damage accumulation-stress or strain controlled? Comparison of the evolution of $D_{E}$ for the same material during a "stress-annealing" experiment and an experiment where annealing is not performed in between straining increments, reveals that these two differ by a factor of $\sim 2$. More specifically, for composite 58A (for which this experiment was performed), the values of $\mathrm{d} D_{E} / \mathrm{d} \varepsilon$ derived from Figs 7 and 9 are 4.8 and 2.3 respectively. This is due to the fact that during the "stress-annealing" experiments the composite stress is kept at relatively low levels in comparison to monotonic tests. This lower rate of damage accumulation during the annealing experiments is non-negligible, however, showing that damage accumulation is neither dependent on stress nor on strain alone in the present composites.

\subsection{Tensile failure}

4.4.1. Failure mode. The majority of the composites presented in this study fail according to the Considere criterion. For angular $\mathrm{Al}_{2} \mathrm{O}_{3}-\mathrm{Al}$ composites, however, a transition to brittle failure (i.e. failure before the Considere criterion is met) was noted for reinforcements smaller or equal to $10 \mu \mathrm{m}$ whereas for the polygonal reinforcements the Considere criterion was always obeyed. The change in fracture mode as a function of particle size in the angular $\mathrm{Al}_{2} \mathrm{O}_{3}-\mathrm{Al}$ composites might be due to the decreasing toughness with decreasing particle size of these composites [80]; however, measured toughness values are relatively high, leading to critical defect sizes that are too large (on the order of $1 \mathrm{~mm}$ ) for this interpretation 
to be plausible. Further studies are necessary for the complete interpretation of this observation.

4.4.2. Failure strain. For composites that fail in a ductile manner, particle shape is the microstructural parameter which has the strongest influence on the failure strain: failure strains do not vary remarkably as a function of average reinforcement size (Table 1). It is also interesting to note that the absolute levels of damage prior to failure, as measured by $D_{E}$, in composites reinforced with angular and polygonal reinforcements are not significantly different [Fig. 7(b)]. These amounts of damage, nevertheless, accumulate at different rates for the different composites. To link the failure strain and the rate of damage accumulation for a damaging material we use the Considere criterion. Since damage results in an insignificant change in volume in the present composites [18], tensile instability occurs when

$$
\frac{\mathrm{d} \sigma}{\mathrm{d} \varepsilon}=\sigma
$$

where $\sigma$ and $\varepsilon$ are the true stress and strain respectively [81]. This relationship can be expressed in terms of the effective stress [defined in equation (4)] as

$$
\frac{\mathrm{d} \tilde{\sigma}}{\mathrm{d} \varepsilon}=\tilde{\sigma}\left(1+\frac{1 \mathrm{~d} D_{E}}{1-D_{E} \mathrm{~d} \varepsilon}\right)
$$

This is a convenient formulation because the constitutive behaviour of the undamaged materials was found to follow a power law hardening relationship (Section 4.2.2). The slope of the effective stressstrain curve (for small elastic strains), can thus be written as

$$
\frac{\mathrm{d} \tilde{\sigma}}{\mathrm{d} \varepsilon}=\frac{n \cdot \tilde{\sigma}}{\varepsilon}
$$

where $n$ is the strain-hardening exponent. Combining equations (6) and (7) provides an expression for $\varepsilon_{\mathrm{f}}$, which reads

$$
\varepsilon_{\mathrm{f}}=\frac{n}{1-\frac{\mathrm{d} \ln \left(1-D_{E}\right)}{\mathrm{d} \varepsilon}}
$$

In Fig. 13, the failure strains of all present composites that fracture due to tensile instability are plotted against equation (8), showing good agreement. The fracture strain of materials that accumulate internal damage during tensile straining is, thus, primarily determined by the rate of damage accumulation $d \mathrm{D} / \mathrm{d} \varepsilon$ (in addition to the intrinsic effect of $n$ ), in agreement with past studies, particularly on $\mathrm{Al}-\mathrm{Si}$ alloys [6, 37] and on PRMMCs [20, 32, 82, 83].

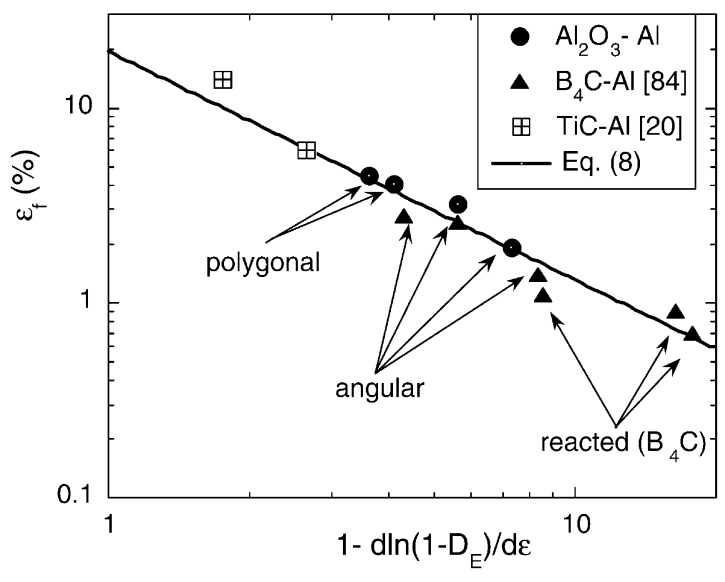

Fig. 13. Failure strain of composites that fail according to Considere's criterion as a function of rate of damage accumulation: theory vs experiment.

This conclusion is further reinforced by experimental data taken from two other studies, also included in Fig. 13. These are:

1. a parallel study of analogous infiltrated composites which consist of pure aluminium and boron carbide particles [84]. In these composites, the rate of damage accumulation was varied by varying the amount of reaction between the matrix and the reinforcement. Increased reaction results in an increased rate of damage accumulation and lower strains to failure (still determined by the Considere criterion). As in the present study, $D_{E}$ was measured for each composite as a function of strain, and power-law hardening with an exponent of $\sim 0.2$ was again determined from their effective tensile curves [85].

2. the experimental study of Kennedy et al. [20] on the effect of processing conditions on the mechanical properties of PRMMCs. These authors have used a casting technique-among others-to produce 10 vol. pct TiC reinforced Al composites; they have also measured the evolution of damage with strain through monitoring of the Young's modulus. Given the similarities in matrix composition and reinforcement geometry between the present composites and those of [20], we assume that both the matrix and the composites in the latter also follow a power-law hardening relationship in the absence of damage [86].

As seen, equation (8) is in agreement with all of the above experimental data.

\section{CONCLUSIONS}

- The initial stiffness of infiltrated $\mathrm{Al}_{2} \mathrm{O}_{3}-\mathrm{Al}$ composites is controlled by the volume fraction 
reinforcement, while the yield stress is a function primarily of particle size. Neither of these properties is significantly influenced by the shape of the reinforcement.

- Internal damage is evident from the onset of plastic deformation and takes two forms: particle cracking and matrix voiding. Particle cracking is mostly a product of particle-particle interactions and of the intrinsic defect population in the starting powder. Increasing particle size and angularity serve to accelerate the accumulation of damage with respect to strain.

- The stiffness-derived damage parameter $\left(D_{E}\right)$ is found to be equivalent to the stress-derived damage parameter $\left(D_{\sigma}\right)$ at all strains, and both damage parameters correlate well to the observed trends in damage accumulation.

- The strain equivalence postulate of continuum damage mechanics adequately describes the effective stress-strain curves of the damaging composites; these curves are of a power-law hardening type with a single strain hardening coefficient equal to 0.2 .

- The failure strain $(\sim 4 \%)$ is higher for composites reinforced with polygonal $\mathrm{Al}_{2} \mathrm{O}_{3}$ particles, all of which fail due to tensile instability. For the angular $\mathrm{Al}_{2} \mathrm{O}_{3}-\mathrm{Al}$ composites average fracture strains are on the order of $2.5 \%$, and a transition in failure mode was determined; for composites containing angular reinforcements $\leq 10 \mu \mathrm{m}$, tensile failure no longer occurs due to tensile instability. For all composites that fail due to necking, the failure strain increases as the average reinforcement size decreases. A simple expression describing the effect of damage on tensile instability predicts the measured failure strains well for these, and other pure aluminium matrix composites.

Acknowledgements-The authors acknowledge funding from the Swiss National Science Foundation, projects No. 2100049119.96 and No. 20-55291.98.

\section{REFERENCES}

1. Sinclair, I. and Gregson, P. J., Mater. Sci. Technol., 1997, 13, 709.

2. Bréchet, Y., Embury, J. D., Tao, S. and Luo, L., Acta metall. mater., 1991, 39, 1781.

3. Caceres, C. H. and Griffiths, J. R., Acta mater., 1996, 44, 25 .

4. Embury, J. D., Newell, J. and Tao, S., in 12th Ris $\phi$ International Symposium on Metallurgy and Materials Science: Metal Matrix Composites-Processing, Microstructure and Properties, ed. N. Hansen, D. Juul-Jensen, T. Leffers, H. Lilholt, T. Lorentzen, A. S. Pedersen, O. B. Pedersen and B. Ralph. Ris $\varnothing$ National Laboratory, Roskilde (Denmark), 1991, p. 317

5. Hadianfard, M. J. and Mai, Y. -W., J. Mater. Sci., 1995, 30, 5335 .

6. Kiser, M. T., Zok, F. W. and Wilkinson, D. S., Acta mater., 1996, 44, 3465.

7. Lee, C. G., Kwon, D. and Lee, S., Metall. mater. Trans., 1997, 28A, 2162.
8. Li, M., Ghosh, S. and Richmond, O., Acta mater., 1999, 47, 3515.

9. Liu, Z. R. and Wang, D. Z., in Eleventh International Conference on Composite Materials, ed. M. L. Scott. Woodhead Publishing Limited, Gold Coast, Queensland, 1997, p. 11.

10. Mummery, P. M. and Derby, B., J. Mater. Sci., 1994, 29, 5615.

11. Rabiei, A., Kim, B. N., Enoki, M. and Kishi, T., Scripta mater., 1997, 37, 801.

12. Singh, P. M. and Lewandowski, J. J., Metal. Trans., 1993, 24A, 2531.

13. Wang, B., Janowski, G. M. and Patterson, B.R., in Advances in Powder Metallurgy and Particulate Materials, ed. A. Lawley and A. Swanson. Metal Power Ind. Fed., Princeton, NJ, 1993, p. 161.

14. Weng, B. J., Chang, S. T. and Shiau, J. S., Scripta metall. mater., 1992, 27, 1127.

15. You, C. P., Thompson, A. W. and Bernstein, I. M., Scripta metall., 1987, 21, 181.

16. Zheng, M., Wu, K., Zhang, W. and Zhao, M., in Eleventh International Conference on Composite Materials, ed. M. L. Scott. Woodhead Publishing Limited, Gold Coast, Queensland, 1997, p. 539.

17. Zhu, J. H., Liaw, P. K., Corum, J. M., Hansen, J. G. R. and Cornie, J. A., Metall. mater. Trans., 1998, 29A, 2855.

18. Kouzeli, M., Weber, L., San Marchi, C. and Mortensen, A., Acta mater., 2001, 49, 497.

19. Whitehouse, A. F. and Clyne, T. W., Acta metall. mater., 1993, 41, 1701.

20. Kennedy, A. R. and Wyatt, S. M., Comp. Sci. Technol., 2000, 60, 307.

21. Lloyd, D. J., Acta metall. mater., 1991, 39, 59.

22. Hunt, W. H. Jr., Brockenbrough, J. R. and Magnusen, P. E., Scripta metall. mater., 1991, 25, 15.

23. Mummery, P. M., Anderson, P., Davis, G. R., Derby, B. and Elliott, K. C., Scripta metall. mater., 1993, 29, 1457.

24. Bourgeois, N., Derrien, K. and Baptiste, D., in Tenth International Conference on Composite Materials, ed. A. Poursartip and K. Street. Whistler, British Columbia, 1995, p. II.

25. Plumtree, A. and Mummery, P., in Tenth International Conference on Composite Materials, ed. A. Poursartip and K. Street. Whistler, British Columbia, 1995, p. II.

26. Hu, M. S., Scripta metall. mater., 1991, 25, 695.

27. Llorca, J., Needleman, A. and Suresh, S., Acta metall. mater., 1991, 39, 2317.

28. Llorca, J., Martin, A., Ruiz, J. and Elices, M., Metall. Trans., 1993, 24A, 1575.

29. Mummery, P. and Derby, B., Mater. Sci. Engng, 1991, A135, 221.

30. Davies, C. H. J., Chen, W. -C., Lloyd, D. J., Hawbolt, E. B., Samarasekera, I. V. and Bricacombe, J. K., Metall. mater. Trans., 1996, 27A, 4113.

31. Yang, J. Y., Zok, F. W. and Levi, C. G., in Processing, Properties and Applications of Cast Metal Matrix Composites, ed. P. K. Rohatgi. TMS, Warrendale, PA, 1996, p. 77.

32. Vedani, M. and Gariboldi, E., Acta mater., 1996, 44, 3077.

33. Lin, $\mathrm{J}$., Li, P. and $\mathrm{Wu}, \mathrm{R}$., in Mechanisms and Mechanics of Composite Fracture, ed. R. B. Bhagat, S. G. Fishman and R. J. Arsenault. ASM International, Pittsburgh, PA, 1993, p. 9.

34. Mummery, P. M., Derby, B. and Scruby, C. B., Acta metall. mater., 1993, 41, 1431.

35. Nayeb-Hashemi, H. and Shan, D., Mater. Sci. Engng, 1999, A266, 8.

36. Song, S., Gray III, G. T. and Roberts, J. A., Metall. Trans., 1996, 27A, 3739.

37. Poole, W. J. and Dowdle, E. J., Scripta mater., 1998, 39, 1281.

38. Llorca, J. and Elices, M., in Intrinsic and Extrinsic Fracture Mechanisms in Inorganic Composite Systems, ed. J. 
J. Lewandowski and W. H. Hunt. The Minerals Metals and Materials Society, Warrendale, PA, 1995, p. 15.

39. Llorca, J., Acta metall. mater., 1995, 43, 181.

40. Nutt, S. R. and Needleman, A., Scripta metall. mater., 1987, 21, 705.

41. Whitehouse, A. F. and Clyne, T. W., Composites, 1993, 24, 256.

42. Wallin, K., Saario, T. and Törrönen, K., Int. J. Fract., 1987, 32, 201.

43. Bourgeois, N., PhD thesis, Ecole Centrale de Paris, 1994.

44. Corbin, S. F. and Wilkinson, D. S., Acta metall. mater., 1994, 42, 1329.

45. Nan, C. W. and Clarke, D. R., Acta mater., 1996, 44, 3801.

46. Whitehouse, A. F. and Clyne, T. W., Acta metall. mater. 1995, 43, 2107.

47. Finot, M., Shen, Y. L., Needleman, A. and Suresh, S., Metall. Trans., 1994, 25A, 2403.

48. Brockenbrough, J. R. and Zok, F. W., Acta metall. mater., 1995, 43, 11

49. Park, T. and Voyiadjis, G. Z., Eng. Fract. Mech., 1997, 56, 623 .

50. Christman, T., Needleman, A. and Suresh, S., Acta metall., 1989, 37, 3029.

51. Kachanov, L., Ivz. Akad. Nauk. SSR Tech. Nauk., 1958, 8, 26.

52. Lemaitre, J., A Course on Damage Mechanics. SpringerVerlag, Berlin, 1992.

53. Skrzypek, J. J. and Ganczarski, A., Modeling of Material Damage and Failure of Structures. Springer-Verlag, Berlin, 1999.

54. Dieter, G. E., in Mechanial Metallurgy. McGraw-Hill, London, 1988, p. 72.

55. Nieh, T. G. and Chellman, D. J., Scripta metall., 1984, 18, 925 .

56. Metals Handbook Vol. 4, 9th ed., ASM International, Metals Park, OH, 1981.

57. Christensen, R. M., Mechanics of Composite Materials. Wiley Interscience, New York, 1979.

58. Moll, F. and Kainer, K. U., in Eleventh International Conference on Composite Materials, ed. M. R. Scott. Woodhead Publishing Limited, Gold Coast, Queensland, 1997, p. 511.

59. Qin, S., Chen, C., Zhang, G., Wang, W. and Wang, Z., Mater. Sci. Engng, 1999, A272, 363.

60. Deppisch, C., Liu, G., Shang, J. K. and Economy, J., Mater. Sci. Engng, 1997, A225, 153.

61. Roatta, A., Turner, P. A., Bertinetti, M. A. and Bolmaro, R. E., Metall. Trans., 1999, 30A, 2875.

62. Meijer, G., Ellyin, F. and Xia, Z., Composites, 2000, B31, 29.

63. Justice, I., Poza, P., Martinez, J. L. and Llorca, J., Metall. mater. Trans., 1996, 27A, 486.

64. Shen, Y. -L., Finot, M., Needleman, A. and Suresh, S.,
Acta metall. mater., 1994, 42, 77.

65. Kamat, S. V., Rollett, A. D. and Hirth, J. P., Scripta metall. mater., 1991, 25, 27.

66. Miller, W. S. and Humphreys, F. J., Scripta metall. mater., 1991, 25, 33.

67. Aikin, R. M. and Christodolou, L., Scripta metall. mater., 1991, 25, 9.

68. Prangnell, P. B., Downes, T., Stobbs, W. M. and Whithers, P. J., Acta metall. mater., 1994, 42, 3425.

69. Boyd, J. D., Evans, R. D., Kleine, G. D. and Tao, S., in Eleventh International Conference on Composite Materials, ed. M. Scott. Woodhead Publishing Limited, Gold Coast, Queensland, 1997, p. 409.

70. Arsenault, R. J. and Shi, N., Mater. Sci. Engng, 1986, 81, 175.

71. Vogelsang, M., Arsenault, R. J. and Fisher, R. M., Metall. Trans., 1986, 17A, 379.

72. Kouzeli, M. and Mortensen, A., Acta mater., submitted for publication.

73. Metals Handbook, Vol. 2, 9th ed., ASM International, Metals Park, OH, 1981.

74. Christman, T., Needleman, A., Nutt, S. and Suresh, S., Mater. Sci. Engng, 1994, A107, 49.

75. Hancock, J. W. and Mackenzie, A. C., J. Mech. Phys. Sol., 1976, 24, 147.

76. Huang, Y. and Chandra, A., Int. J. Solids Struct., 1998, 35, 2475.

77. Sumitomo Chemical Co Ltd., Advanced Ceramics-Product Information, 1996.

78. Chen, C. R., Qin, S. Y., Li, S. X. and Wen, J. L., Mater. Sci. Engng, 2000, A278, 96.

79. Timoshenko, S. P. and Goodier, J. N., in Theory of Elasticity, 3rd ed. McGraw-Hill, Singapore, 1970, p. 409.

80. Miserez, A., Rossoll, A., Marchi, C. S., Weber, L. and Mortensen, A., in Advances in Mechanical Behaviour, Plasticity and Damage, ed Miannay, D., Costa, P., Francois, D. and Pineau, A. Elsevier, Amsterdam, 2000, p. 723.

81. Weber, L., Kouzeli, M., San Marchi, C. and Mortensen, A., Scripta mater., 1999, 41, 549.

82. Manoharan, M. and Gupta, M., Composites Part B, 1999, 30, 107.

83. Manoharan, M., Gupta, M., Lai, M. O. and Saravanaranganathan, D., Mater. Sci. Technol., 2000, 16, 670.

84. Kouzeli, M., San Marchi, C. and Mortensen, A., Mater. Sci. Engng, submitted for publication.

85. Kouzeli, M., PhD thesis (No 2348), Swiss Federal Institute of Technology in Lausanne, 2001.

86. Bao, G., Hutchinson, J. W. and McMeeking, R. M., Acta metall. mater., 1991, 39, 1871.

87. H. E. Boyer and T. L. Gall (ed.), Metals Handbook, Desk Edition. ASM International, Metals Park, OH 1985.

88. Shneider, S. J., ed. Engineered Materials Handbook, Vol. 4. ASM International, Metals Park, OH 1991. 